\title{
Effects of Reversible Inactivation of the Neonatal Ventral Hippocampus on Behavior in the Adult Rat
}

\author{
Barbara K. Lipska, Nader D. Halim, Pavan N. Segal, and Daniel R. Weinberger \\ Clinical Brain Disorders Branch, Intramural Research Program, National Institute of Mental Health, National Institutes of \\ Health, Bethesda, Maryland 20892-1385
}

\begin{abstract}
Rats with neonatal excitotoxic damage of the ventral hippocampus display in adulthood a variety of abnormalities reminiscent of schizophrenia and are used as an animal model of this disorder. In the present study, we hypothesized that transient inactivation of ventral hippocampal activity during a critical developmental period may be sufficient to disrupt normal maturation of relevant brain systems and produce similar lasting behavioral changes. We infused tetrodotoxin (TTX) or artificial CSF into the ventral hippocampus on postnatal day 7 (P7) and assessed behavioral changes in response to stress, amphetamine, and (+)-5-methyl-10,11-dihydro-5H-dibenzo [a,d] cyclohepten-5,10-imine maleate in juvenile (P35) and young adult (P56) rats. In adulthood, rats infused neonatally with TTX
\end{abstract}

We have shown previously that rats with a neonatal excitotoxic lesion of the ventral hippocampus display in adulthood a variety of abnormalities reminiscent of schizophrenia and can be used as an animal model of this disorder (for review, see Lipska and Weinberger, 2000). In this model, we produced injury of the hippocampus, a brain area consistently implicated in human schizophrenia (Falkai and Bogerts, 1986; Suddath et al., 1990; Eastwood and Harrison, 1995, 1998; Eastwood et al., 1995, 1997; Benes, 1999; Weinberger, 1999), and hypothesized that this developmental disruption would alter maturational processes in the widespread cortical and subcortical circuitry in which the hippocampus participates. The excitotoxic lesion involved regions of the hippocampus that directly project to the prefrontal cortex (i.e., the ventral hippocampus and ventral subiculum) (Jay et al., 1989; Carr and Sesack, 1996). These regions correspond to the anterior hippocampus in humans, an area that shows anatomic abnormalities in schizophrenia (Suddath et al., 1990; Harrison, 1999). Rats with a neonatal lesion of the ventral hippocampus exhibit in adulthood behaviors suggesting dysregulation of the dopamine system, as well as various electrophysiological, molecular, and morphological changes in the prefrontal cortex mimicking abnormalities in the schizophrenic brain. These rats also show enhanced sensitivity to glutamate antagonists [(+)-5-methyl10,11-dihydro-5H-dibenzo [a,d] cyclohepten-5,10-imine maleate (MK-801) and phencyclidine], deficits in prepulse inhibition of startle and latent inhibition, impaired social behaviors, and working memory deficits (Lipska and Weinberger, 1993, 1994a,b;

\footnotetext{
Received Oct. 17, 2001; revised Dec. 1, 2001; accepted Dec. 31, 2001.

Correspondence should be addressed to B. K. Lipska, Clinical Brain Disorders Branch, Intramural Research Program, National Institute of Mental Health, National Institutes of Health, 10 Center Drive, Building 10, Room 4N306, Bethesda, MD 20892-1385. E-mail: lipskab@intra.nimh.nih.gov.

Copyright (C) 2002 Society for Neuroscience $0270-6474 / 02 / 222835-08 \$ 15.00 / 0$
}

displayed motor hyperactivity after pharmacological stimulation and after stress compared with sham controls. Analogous TTX infusions in adult animals did not alter these behaviors later in life. These data suggest that transient loss of ventral hippocampal function during a critical time in maturation of intracortical connections permanently changes the development of neural circuits mediating certain dopamine- and NMDA-related behaviors. These results represent a potential new model of aspects of schizophrenia without involving a gross anatomic lesion.

Key words: tetrodotoxin; animal model; schizophrenia; amphetamine; MK-801; locomotion

Lipska et al., 1995; Becker et al., 1999; Grecksch et al., 1999; Hori et al., 1999; Al-Amin et al., 2001), phenomena that also show many parallels with schizophrenia. Notably, similar lesions inflicted in adult rats do not produce analogous changes, suggesting that the ventral hippocampus per se is not necessary for normal performance in these behavioral conditions. Furthermore, removal of prefrontal neurons in adult animals with the neonatal hippocampal lesion restores some of the behaviors (e.g., motor activity in response to amphetamine), suggesting that aberrant development of the prefrontal cortex in the context of early damage to the hippocampus may be a critical factor in the onset of the syndrome (Lipska et al., 1998). Other evidence of molecular and electrophysiological changes in the medial prefrontal cortex of these animals supports this interpretation (Bertolino et al., 1999; O’Donnell et al., 1999; Stine et al., 2001).

This developmental lesion model appears to have predictive validity, because chronic treatment with antipsychotic drugs normalizes some abnormal behavioral changes (Lipska and Weinberger, 1994a; Sams-Dodd et al., 1997; Al-Amin et al., 2000), as well as face validity in terms of behavioral, molecular, and pharmacological phenomena and the temporal course of the clinical disorder. As a model of developmental pathology, however, it lacks construct validity, because the schizophrenic brain, despite the evidence for subtle abnormalities in the structure and function of the hippocampus, certainly does not manifest a "lesion" analogous to that produced in this model.

In the present study, we hypothesized that transient inactivation of the ventral hippocampus during a critical period of development that produces subtle, if any, anatomic changes in the hippocampus may be sufficient to disrupt normal maturation of the prefrontal cortex (and perhaps other interconnected latematuring regions). We explored whether this developmental disruption would, in turn, trigger behavioral changes similar to those 
observed in animals with the permanent excitotoxic lesion. We used tetrodotoxin (TTX), a potent and specific blocker of voltagegated sodium channels with an action that is fully reversible, to inactivate the ventral hippocampus on postnatal day 7 (P7), an important time for refinement of intracortical connections, and then assessed the behavioral changes that this treatment might have evoked later in life.

\section{MATERIALS AND METHODS}

Surgery. All procedures were performed in accordance with the National Institutes of Health guidelines for use and care of laboratory animals. Pregnant Sprague Dawley rats were obtained at 15 d gestation (Harlan, Indianapolis, IN). On P7 (weight 15-18 gm), male pups were randomized to sham or TTX status and anesthetized by hypothermia (placed on ice for 10-20 min). Rats were immobilized by taping onto a styrofoam platform that was positioned in the ear bars of the Kopf stereotaxic frame (David Kopf Instruments, Tujunga, CA). In pilot experiments, we determined that TTX injected into the neonatal ventral hippocampus in doses of $>3 \mathrm{ng} /$ side resulted in some minimal structural damage in the injection site that exceeded the damage seen in sham animals. Thus, in the following experiments, we infused $3 \mathrm{ng}$ of TTX per side into the neonatal brain. An incision was made in the skin, and either $3 \mathrm{ng}$ of TTX (Sigma, St. Louis, MO) in $0.3 \mu$ l of artificial CSF (aCSF) or aCSF alone (in sham) was infused bilaterally into the ventral hippocampus at a rate of $0.15 \mu \mathrm{l} / \mathrm{min}$ at anteroposterior (AP) -3.0 , mediolateral (ML) \pm 3.5 , and ventrodorsal (VP) $-5.0 \mathrm{~mm}$, relative to bregma. The needle was withdrawn $3 \mathrm{~min}$ after completion of the infusion. The pups were placed under a warming lamp and then returned to their mothers. Rats were weaned 3 weeks after surgery (P28) and separated by injection status (sham or TTX). Adult rats (weight, $250 \mathrm{gm}$ ) received $6 \mathrm{ng} / 0.6 \mu \mathrm{l}$ TTX inf usions at coordinates AP $-4.4, \mathrm{ML} \pm 5.0$, and VD $-7.0 \mathrm{~mm}$. Neonatally infused rats were tested at P35 and P56 (i.e., 4 and 7 weeks after surgery). Adult rats were tested 8 weeks after infusion. For behavioral testing, we used three independent cohorts of neonatal rats (total $n=$ 114 ) and one group of rats injected with TTX in adulthood (total $n=23$ ). Some of these rats were used for multiple testing (see Results for details). For Black-Gold (Histo-Chem, Jefferson, AR) staining, a separate group of neonatally TTX-infused rats was used $(n=8$ sham and 8 TTX). At P42, these rats were deeply anesthetized with Nembutal and transcardially perfused with $4 \%$ paraformaldehyde.

Behavioral testing. Various parameters of motor activity (horizontal activity, which was defined as the number of beam interruptions in the horizontal sensor; distance traveled in centimeters; vertical activity, which was defined as the number of beam interruptions in the vertical sensor; center distance in centimeters that an animal traveled while in the center of the cage) were recorded using a computerized photocell system. On the day of testing, rats were moved to the testing room in their home cages. The testing field consisted of Plexiglas cages $(42 \times$ $42 \times 30 \mathrm{~cm}$ ) equipped with photocell monitors (model RXYZCM; Omnitech, Columbus, OH). Animals were tested during their light cycle between 8:00 A.M. and 4:00 P.M. In amphetamine experiments, rats were exposed to environmental novelty (placed in novel monitors) for 60 $\mathrm{min}$, injected with saline $(1 \mathrm{ml} / \mathrm{kg}$, i.p.) and monitored for $60 \mathrm{~min}$, and finally given amphetamine $(1.5 \mathrm{mg} / \mathrm{kg}$, i.p.) and monitored for an additional $90 \mathrm{~min}$. The same neonatally injected rats were tested at P35 and P56, except for one group that was tested only once in adulthood to address the possibility that the second administration of amphetamine produces behavioral sensitization. In MK-801 experiments, after $1 \mathrm{hr}$ of adaptation in the testing room, animals were placed in a photocell cage for a $30 \mathrm{~min}$ habituation period followed by a $30 \mathrm{~min}$ recording after a subcutaneous saline injection. Then neonatally sham and TTX-treated rats were randomly assigned to receive one of two doses of MK-801 (0.1 or $0.2 \mathrm{mg} / \mathrm{kg}$, s.c.). Rats inf used with TTX in adulthood were tested with only one dose of MK-801 $(0.2 \mathrm{mg} / \mathrm{kg})$. Animals were then monitored for $2 \mathrm{hr}$. MK-801 testing was conducted 4 weeks after the amphetamine experiment.

For social interaction tests, rats were tested in pairs (two unfamiliar rats of the same treatment, sham or TTX, which were always housed in different home cages) during a dark cycle (between 8:00 P.M. and 11:30 P.M.). Rats were placed in a large open field (a black painted wooden box filled with bedding previously exposed to rat odor; dimensions $40 \times$ $100 \times 150 \mathrm{~cm})$ for $10 \mathrm{~min}$. A red light bulb $(25 \mathrm{~W})$ was placed over the center of a testing arena. Two investigators blind to treatment status scored the following behaviors at $1 \mathrm{~min}$ intervals ( 1 point for the occurrence of a particular type of behavior during a $1 \mathrm{~min}$ interval; maximum score 10): grooming, aggression (biting, fighting, threats, mounting), investigating each other (sniffing, nosing, following, climbing over or going under), and rearing.

Histology. Rats were killed by decapitation at the end of the last behavioral testing, and brains were rapidly removed and frozen at $-80^{\circ} \mathrm{C}$. Portions containing the hippocampus were sectioned into $20 \mu \mathrm{m}$ slices on a cryostat, and slices were Nissl-stained. In every subject, at least 30 coronal slices through the hippocampus [corresponding to plates of the rat atlas of Paxinos and Watson (1986)] were inspected for tissue loss, neuronal loss, and gliosis using light microscopy. Damaged areas were mapped onto coronal sections in the atlas of Paxinos and Watson (1986). The extent of damage was evaluated by an investigator blind to the status of an animal, and the results of behavioral testing were assessed using an arbitrary scoring system $(0$, no discernible damage; 1 , slight cannula tracks; 2, minimal neuronal loss in the infusion area in excess of a cannula track area but extending $<0.5 \mathrm{~mm}^{2}$; and 3 , neuronal loss in the infusion area extending between 0.5 and $1 \mathrm{~mm}^{2}$ ).

For Black-Gold histochemistry of myelinated fibers (Schmued and Slikker, 1999), brains obtained at P42 were fixed in $4 \%$ paraformaldehyde, cryoprotected in $20 \%$ glycerol, embedded in gelatin, and cut into $40 \mu \mathrm{m}$ sections with a sliding microtome. We elected to process brains at $\mathrm{P} 42$, because our previous studies with the neonatal excitotoxic lesion of the ventral hippocampus prepared as described previously (Lipska et al., 1993) showed marked widespread hypomyelination at this time in development (see Fig. 2H,I). Others found that Black-Gold is a sensitive method for detection of pathology in excitotoxin-induced myelin morphology (Schmued and Slikker, 1999). Sections were stained in a $0.2 \%$ solution of Black-Gold at $60^{\circ} \mathrm{C}$ for $12 \mathrm{~min}$ until cortical fine parallel fibers were clearly visible. Sections were then mounted onto gelatinsubbed slides, air-dried, and counterstained for the Nissl substance to visualize the cell bodies. Sections were matched using anatomical landmarks [at bregma $-5.6 \mathrm{~mm}$, corresponding to plate 40 of the rat atlas of Paxinos and Watson (1986)] and inspected by light microscopy. Images from hippocampal regions $(200 \times$ magnification) were captured using a DKC-5000 digital photo camera (Sony, Tokyo, Japan) with Adobe Photoshop 5.0 software (Adobe Systems, San Jose, CA) on a Dell (Round Rock, TX) computer. Images were then analyzed using NIH Image by an investigator blind to treatment status of the animal. Optical density was measured in the following subregions of the hippocampal formation and surrounding areas: the entorhinal cortex, subiculum, CA2 area (layers: oriens, pyramidal cells, stratum radiatum, and alveus).

Statistical analysis. The extent of damage in Nissl-stained slices obtained from sham and TTX groups was compared using nonparametric Mann-Whitney tests. The regression analysis was conducted to test whether extent of damage predicted motor activity in TTX-treated groups. The Black-Gold histochemical data were analyzed by a two-way ANOVA with subregions of the hippocampus (region) as a repeated measure and treatment (sham, TTX) as an independent factor. Behavioral data from amphetamine experiments were statistically analyzed with a three-way ANOVA with treatment (sham or lesion) as an independent factor and age (P35 and P56) and testing interval (novelty, saline, amphetamine) as repeated measures. Data from MK-801 experiments were analyzed with a three-way ANOVA with treatment (sham or lesion) and dose $(0.1$ and $0.2 \mathrm{mg} / \mathrm{kg})$ as independent factors and testing interval (saline injection and MK-801 injection) as a repeated measure. Fisher's PLSD post hoc tests were used where appropriate. Scores for social behaviors were summed to yield a total score for a pair of rats for a given behavior and analyzed using nonparametric Mann-Whitney tests. The levels of significance were set at $p<0.05$.

\section{RESULTS}

\section{Histology}

No discernible damage or gliosis (except for cannula tracks in rats from both sham and TTX groups) was detected in the ventral hippocampus or surrounding areas in Nissl-stained slices obtained from adult rats with neonatal infusions of TTX (Fig. $1 A-C$, TTX; $D-F$, sham) (scores $0.45 \pm 0.1$ for sham controls and $0.5 \pm 0.2$ for TTX rats; $p>0.8$ ). In rats treated with TTX in adulthood, some minimal neuronal loss and gliosis was seen in the inf usion site (Fig. $1 G-I$ ). This damage significantly exceeded the damage detected in sham animals (scores $1.4 \pm 0.3$ for TTX rats 

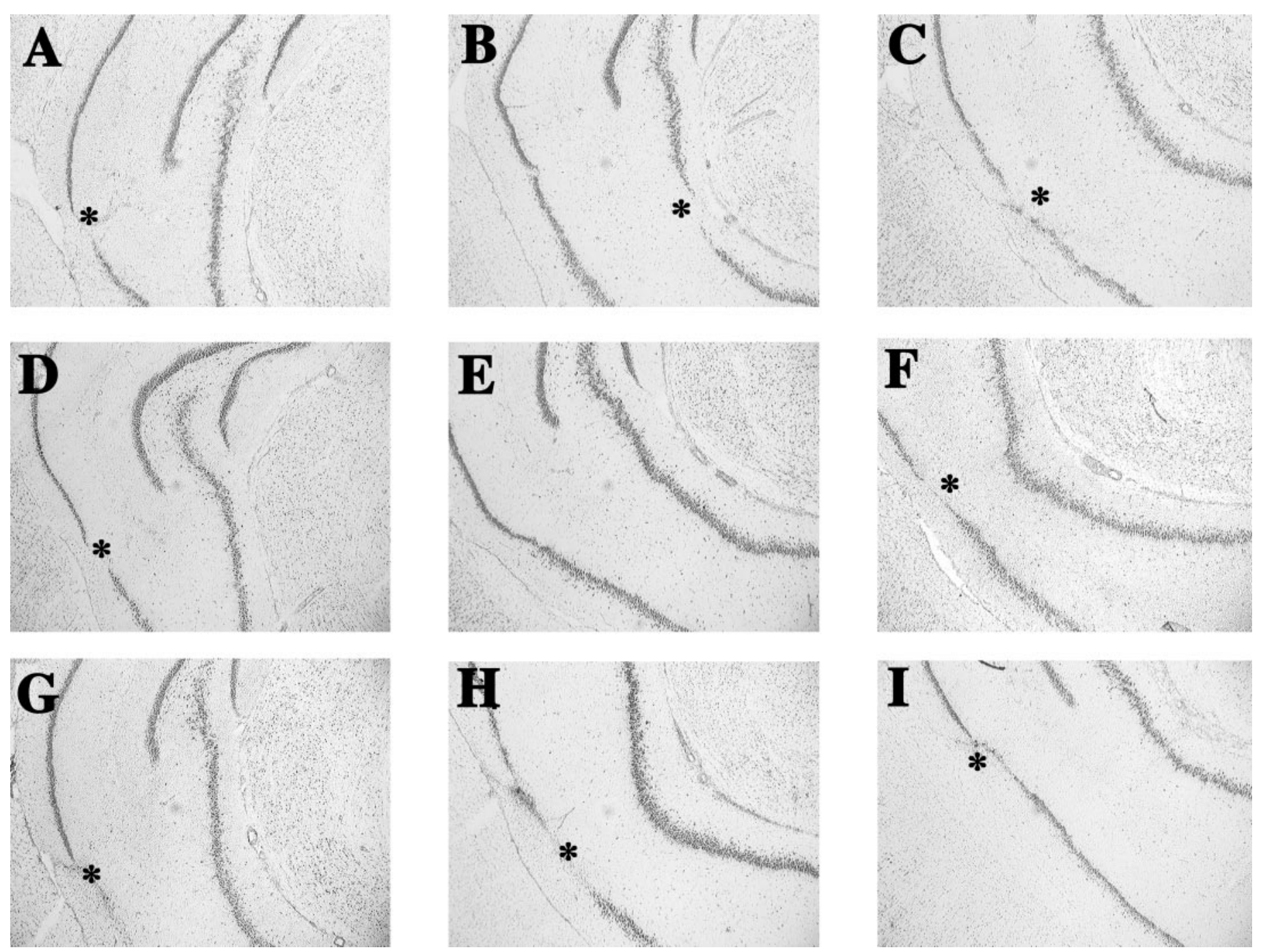

Figure 1. Photomicrographs of Nissl-stained sections through the hippocampus of adult rats with neonatal TTX $(A-C)$, vehicle $(D-F)$, and adult TTX $(G-I)$ inf usions. The images from left to right in each row represent the anterior to posterior extent of the hippocampus from approximately bregma -4.8 $\mathrm{mm}(A, D, G)$ to bregma $-6.0 \mathrm{~mm}(C, F, I)$ according to the rat atlas of Paxinos and Watson (1986). Asterisks denote areas of neuronal loss and/or tissue disruption caused by cannula insertion.

and $0.6 \pm 0.2$ for sham controls; $p<0.05$ ). There was no correlation in these animals, however, between extent of TTXinduced injury and motor activity (all $R^{2}<0.04 ; p>0.5$ ).

No significant differences between the sham and TTX groups were detected in the intensity of Black-Gold staining in any of the inspected subregions of the hippocampal formation (an infusion site) or surrounding areas, suggesting that the fibers leaving, coming to, or passing through the hippocampus have developed normal myelin. A two-way ANOVA with region as a repeated measure and treatment (sham or TTX) as an independent factor revealed a significant effect of region $\left(F_{(5,15)}=179.9 ; p<0.0001\right)$, no effect of treatment $\left(F_{(1,15)}=0.01 ; p=0.9\right)$, and no significant effect of region by treatment interaction $\left(F_{(5,15)}=0.29 ; p=0.9\right)$ (Fig. 2).

\section{Amphetamine experiment}

In the first cohort of neonatal rats (cohort $1, n=21$ sham and 23 TTX rats), a three-way ANOVA showed significant treatment $\left(F_{(1,43)}=7.9,5.5,7.0 ; p<0.05\right)$, age $\left(F_{(1,43)}=19.1,27.9,46.3 ; p<\right.$ $0.001)$, and testing interval $\left(F_{(2,43)}=391,237,138 ; p<0.0001\right)$ effects as well as significant treatment $\times$ testing interval interac- tions $\left(F_{(2,43)}=4.5,4.4,5.5 ; p<0.05\right)$ for horizontal activity, total distance, and center distance, respectively. Interactions of treatment $\times$ age $\left(F_{(2,43)}=8.7\right)$ and treatment $\times$ age $\times$ testing interval $\left(F_{(2,43)}=5.5\right)$ were significant $(p<0.01)$ for center distance but not for horizontal activity $\left(F_{(2,43)}=2.7,0.1 ; p=0.1,0.88\right.$, respectively) or total distance $\left(F_{(2,43)}=4.4,0.99 ; p=0.08,0.3\right.$, respectively). For vertical activity, there was a significant testing interval effect $\left(F_{(2,43)}=176 ; p<0.001\right)$ but no significant treatment $\left(F_{(1,43)}=3.5 ; p=0.06\right)$ or age $\left(F_{(1,43)}=1.2 ; p=0.2\right)$ effects and no significant interactions. Post hoc tests showed that TTX animals were hyperactive in response to novelty (for total distance, center distance), saline injection (horizontal activity, total distance), and amphetamine $(1.5 \mathrm{mg} / \mathrm{kg}$ ) (horizontal activity, total distance, and center distance) in early adulthood (P56) but not as juveniles (P35) ( $p<0.05$ compared with sham controls) (Fig. 3).

To replicate these findings, we used a second group of rats (cohort 2, $n=20$ sham and 20 TTX rats). In this cohort, we confirmed that TTX animals displayed hyperactive behavior in response to novelty (in total distance, vertical activity, and center 
$\mathbf{A}$

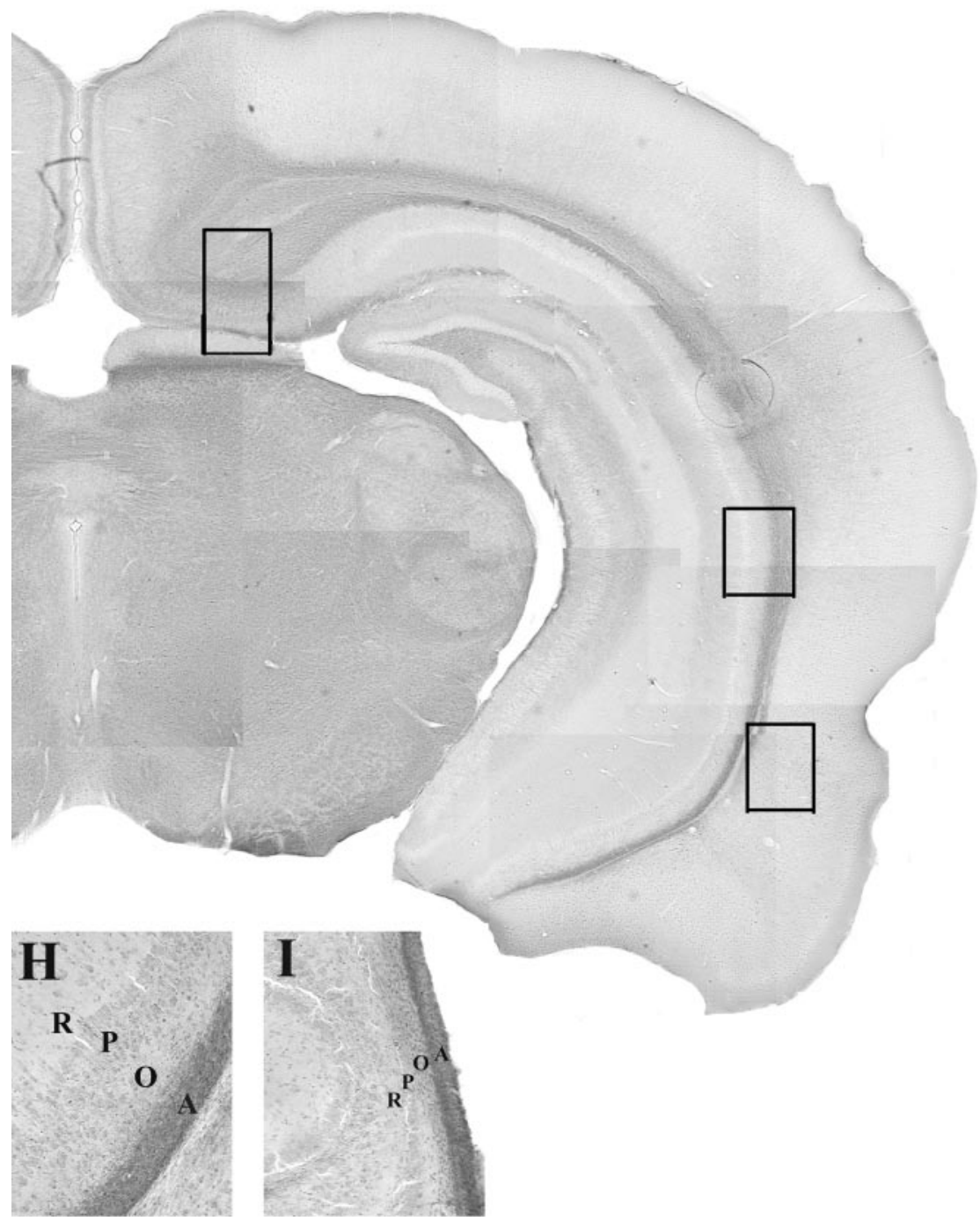

B
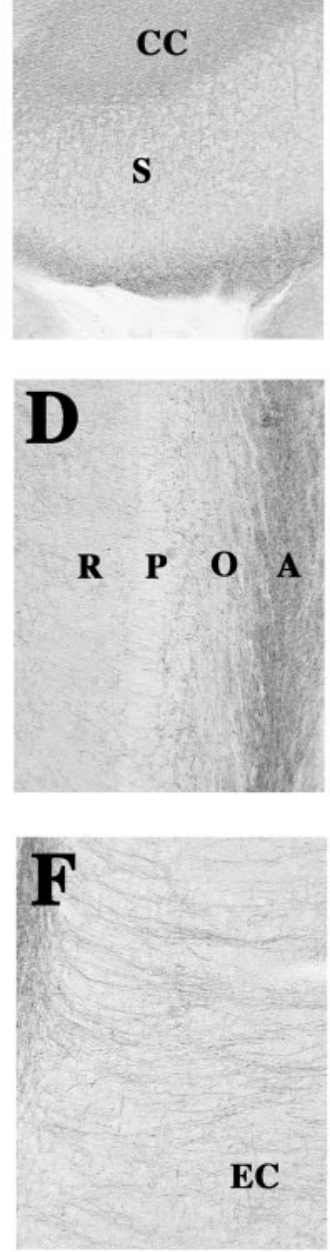

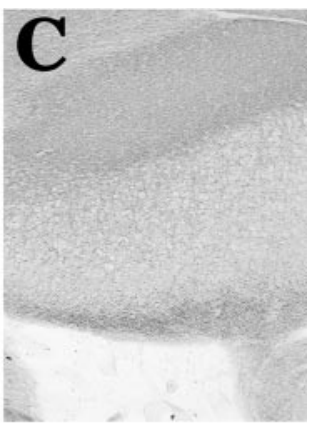

$\mathbf{E}$

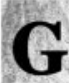

Figure 2. Photomicrographs of Black-Gold-stained sections through the hippocampal formation of sham $(A, B, D, F)$ and neonatally TTX-infused $(C$, $E, G)$ rats killed at postnatal day 42. A, A composite of a Black-Gold-stained coronal slice at $40 \times$ magnification through the brain of a sham animal cut at the level corresponding to plate 40 of the rat atlas of Paxinos and Watson (1986) (bregma $-5.6 \mathrm{~mm})$. Insets, Higher magnifications (200×) of dorsal subiculum $(B, C), \mathrm{CA} 2(D, E)$, and entorhinal cortical $(F, G)$ regions from sham and TTX brains, respectively. Higher magnifications $(200 \times)$ of the CA2 from sham $(H)$ and neonatally (P7) ibotenic acid-lesioned rats $(I)$ were prepared as described by Lipska et al. (1993); rats were killed at postnatal day 42. $C C$, Corpus callosum; $E C$, entorhinal cortex; $S$, subiculum. CA2 area layers: $O$, Oriens; $P$, pyramidal cells; $R$, stratum radiatum; $A$, alveus.

distance) and amphetamine (all four behavioral parameters) as young adults (P56) but not as juveniles (P35) (data not shown). After saline, however, this group of TTX rats did not differ from sham controls in any of the parameters recorded. A three-way ANOVA showed significant treatment $\left(F_{(1,39)}=7.8,8.0 ; p<\right.$ $0.05)$, age $\left(F_{(1,39)}=14.5,18.3 ; p<0.01\right)$, and testing interval $\left(F_{(2,39)}=136,129 ; p<0.001\right)$ effects as well as significant treatment $\times$ age $\left(F_{(1,39)}=6.1,7.2 ; p<0.05\right)$, treatment $\times$ testing interval $\left(F_{(2,39)}=5.9,4.9 ; p<0.05\right)$, and treatment $\times$ age $\times$ testing interval $\left(F_{(2,39)}=5.2,6.0 ; p<0.05\right)$ interactions for total distance and center distance, respectively. For horizontal and vertical activity, there were significant treatment $\left(F_{(1,39)}=4.7\right.$, $4.3 ; p<0.05)$, age $\left(F_{(1,39)}=9.5,8.2 ; p<0.05\right)$, and testing interval $\left(F_{(2,39)}=102,111 ; p<0.01\right)$ effects, significant treatment $\times$ testing interval $\left(F_{(2,39)}=4.4,3.9 ; p<0.05\right)$ interactions, but no significant treatment $\times$ age and treatment $\times$ age $\times$ testing interval (all $F$ values $<1.0 ; p>0.2$ ) interactions.

To elucidate whether TTX rats were hyperactive at an older age because of the sensitization to the initial dose of amphetamine administered during a juvenile period, we used a third group of neonatally injected rats (cohort $3, n=13$ sham and 17 TTX rats), which were tested only in adulthood. TTX rats in this group showed hyperactivity compared with sham animals in all three testing conditions $(p<0.05)$ (Fig. 4). A two-way ANOVA with treatment (sham or TTX) as an independent factor and testing interval (novelty, saline, amphetamine) as a repeated measure revealed significant effects of treatment and significant treatment $\times$ testing interval interactions for total distance $\left(F_{(1,29)}=5.2, p<0.05 ; F_{(2,29)}=7.3, p<0.01\right)$, vertical activity $\left(F_{(1,29)}=4.9, p<0.05 ; F_{(2,29)}=6.9, p<0.01\right)$, and center 


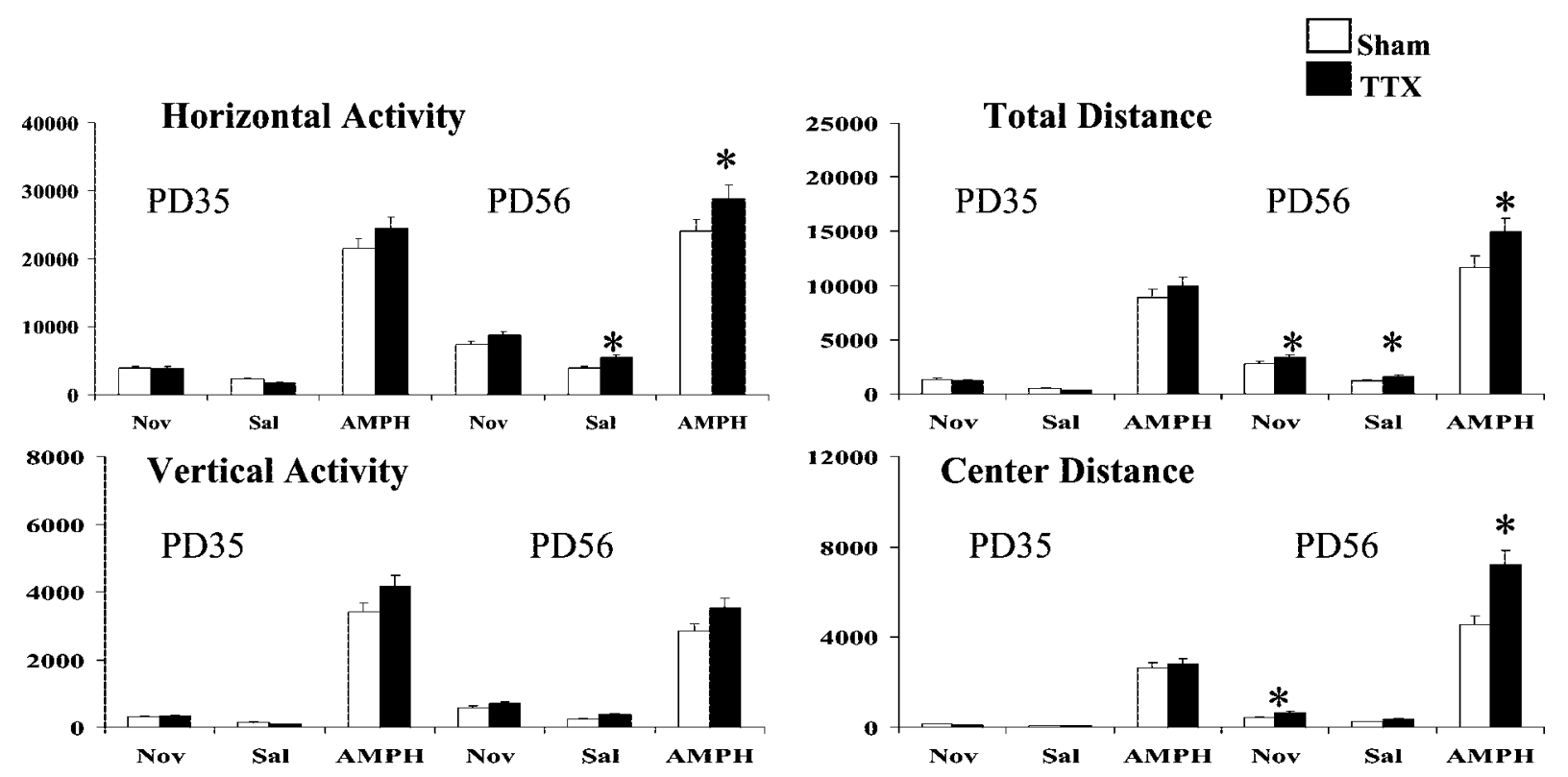

Figure 3. Locomotor activity (horizontal activity, total distance traveled, vertical activity, center distance) in rats with neonatal TTX infusions. The same rats were tested in photocell monitors at P35 and P56 after exposure to novelty (Nov) and after saline injection (Sal) and amphetamine administration $(A M P H, 1.5 \mathrm{mg} / \mathrm{kg}$, i.p.). TTX-infused rats were significantly more active than sham rats at P56 ( $p<0.05 ; n=21-23$ per group).
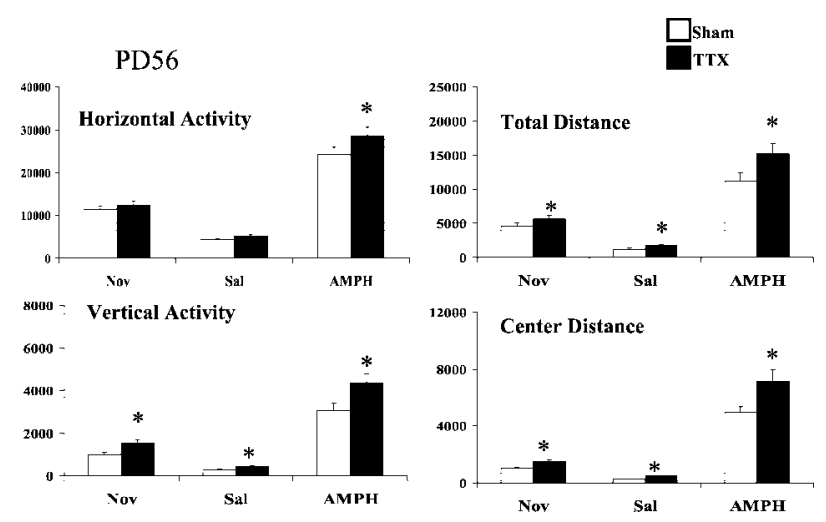

Figure 4. Locomotor activity (horizontal activity, total distance traveled, vertical activity, center distance) in rats with neonatal TTX infusions. Rats were tested in photocell monitors only at P56 after exposure to novelty (Nov) and after saline injection ( Sal) and amphetamine administration $(A M P H, 1.5 \mathrm{mg} / \mathrm{kg}$, i.p.). TTX-inf used rats were significantly more active than sham rats $\left({ }^{*} p<0.05 ; n=13-16\right.$ per group).

distance $\left(F_{(1,29)}=5.6, p<0.05 ; F_{(2,29)}=7.1, p<0.01\right)$. For horizontal activity, there was a significant treatment effect $\left(F_{(1,29)}=4.2 ; p<0.05\right)$ but no significant treatment $\times$ testing interval interaction.

In contrast, animals that received injections of TTX in adulthood (cohort 4, $n=9$ sham and 14 TTX rats) did not display hyperactive behaviors for any of the parameters recorded in any of the conditions (data not shown). A two-way ANOVA with treatment as an independent factor and testing interval as a repeated measure did not show significant treatment effects or significant treatment $\times$ testing interval interactions for any of the four parameters measured [horizontal activity $\left(F_{(1,22)}=1.5, p>\right.$ $\left.0.2 ; F_{(2,22)}=0.15, p>0.5\right)$, total distance $\left(F_{(1,22)}=1.8, p=0.2\right.$; $\left.F_{(2,22)}=0.58, p>0.5\right)$, vertical activity $\left(F_{(1,22)}=0.32\right.$, $\left.p>0.5 ; F_{(2,22)}=0.88, p>0.4\right)$, and center distance $\left(F_{(1,22)}=1.4\right.$, $\left.\left.p>0.2 ; F_{(2,22)}=1.1, p>0.3\right)\right]$ for the main effect and interaction, respectively.

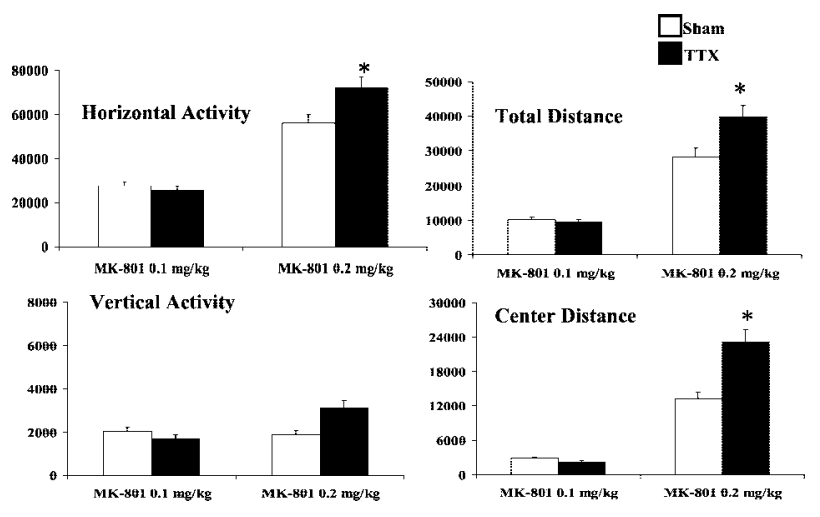

Figure 5. Locomotor activity (horizontal activity, total distance traveled, vertical activity, center distance) in rats with neonatal TTX inf usions. Motor activity was recorded in response to MK-801 (0.1 and 0.2 $\mathrm{mg} / \mathrm{kg}$, s.c.) 11 weeks after TTX infusion. TTX rats that were administered $0.2 \mathrm{mg} / \mathrm{kg}$ MK-801 showed exaggerated motor hyperactivity compared with sham controls ( $* p<0.05 ; n=5-8$ per group).

\section{MK-801 experiment}

Rats injected with TTX as neonates and tested once with amphetamine (i.e., cohort 3) were injected with saline and then treated with MK-801 (0.1 and $0.2 \mathrm{mg} / \mathrm{kg}) 4$ weeks after the amphetamine experiment (i.e., 11 weeks after infusion). TTX rats given a single higher dose $(0.2 \mathrm{mg} / \mathrm{kg})$ of MK- 801 showed exaggerated motor hyperactivity compared with sham controls $(p<0.05)$ (Fig. 5). A lower dose of MK-801 (0.1 mg/kg), which markedly enhanced activity in both groups compared with a saline injection, did not evoke a differential response in TTX rats compared with sham animals $(p>0.5)$. A three-way ANOVA revealed the following effects: for horizontal activity, a significant dose effect $\left(F_{(1,29)}=50.3 ; p<0.0001\right)$, no significant treatment effect $\left(F_{(1,29)}=1.6 ; p>0.05\right)$, and no significant dose $\times$ treatment $\left(F_{(1,29)}=2.6 ; p=0.1\right)$ or dose $\times$ treatment $\times$ testing interval $\left(F_{(2,29)}=2.7 ; p=0.1\right)$ interactions; for total distance, 
significant dose $\left(F_{(1,29)}=57.1 ; p<0.0001\right)$ and testing interval effects $\left(F_{(2,29)}=137 ; p<0.0001\right)$, no significant treatment effect $\left(F_{(1,29)}=2.9 ; p=0.09\right)$, and no significant dose $\times$ treatment $\left(F_{(1,29)}=3.2 ; p=0.08\right)$, treatment $\times$ testing interval $\left(F_{(2,29)}=\right.$ $2.5 ; p=0.1)$, or dose $\times$ treatment $\times$ testing interval $\left(F_{(2,29)}=3.6\right.$; $p=0.07)$ interactions; for center distance, significant dose $\left(F_{(1,29)}=133 ; p<0.0001\right)$, treatment $\left(F_{(1,29)}=12.4 ; p<0.01\right)$, and testing interval $\left(F_{(2,29)}=180 ; p<0.0001\right)$ effects and significant dose $\times$ treatment $\left(F_{(1,29)}=14.8 ; p<0.001\right)$, dose $\times$ testing interval $\left(F_{(1,29)}=113 ; p<0.001\right)$, treatment $\times$ testing interval $\left(F_{(1,29)}=9.6 ; p<0.005\right)$, and dose $\times$ treatment $\times$ testing interval $\left(F_{(2,29)}=13.0 ; p=0.001\right)$ interactions. No significant effects were detected for vertical activity.

Finally, animals with TTX or aCSF injections given in adulthood who had been tested once before in the amphetamine experiment were exposed to MK-801 4 weeks later (i.e., 12 weeks after infusion). TTX rats responded to $0.2 \mathrm{mg} / \mathrm{kg} \mathrm{MK}-801$ in a manner similar to sham controls (data not shown). There were no significant effects of treatment for horizontal activity, total distance, vertical activity, or center distance and no significant interactions (all $\left.F_{(1,22)}<0.9 ; p>0.3\right)$.

\section{Social behaviors}

Rats with neonatal TTX or aCSF injections from cohort 2 tested previously twice (at P35 and P56) in amphetamine experiments were assessed in a social interaction test 4 weeks later (i.e., 11 weeks after infusion). We used 7 pairs of sham rats and 10 pairs of TTX rats. Despite large mean differences [i.e., more grooming (by $100 \%$; $p<0.1$ ), rearing (by 20\%; $p<0.1$ ), and less investigating of an unfamiliar partner (by $14 \%$; $p<0.1$ ) by the TTXtreated rats than by sham controls], none of these differences reached statistical significance (data not shown).

\section{DISCUSSION}

Our results demonstrate that reversible pharmacological blockade of ventral hippocampal activity in the developing rat has longterm effects on the patterns of motor activity in response to the mild stress of a novel environment, amphetamine, and an NMDA antagonist, MK-801. Analogous functional disconnection of the ventral hippocampus in adult animals, however, did not affect these behaviors later in life. It should be noted, however, that adult-treated animals were tested 8 weeks after the infusion, whereas neonatal rats were tested at 7 weeks after treatment and later. Thus, although unlikely, it cannot be excluded that the adult TTX-treated rats might have manifested behavioral changes $7 \mathrm{~d}$ earlier. These data suggest that transient loss of ventral hippocampal function during an early maturational period permanently changes the development of neural circuits mediating certain dopamine- and NMDA-related behaviors. Notably, changes triggered by the neonatal blockade of neuronal activity by TTX emerge relatively late in development, during young adulthood. The overall characteristics of behavioral changes and their temporal patterns are reminiscent of the disturbances associated with the permanent excitotoxic lesion of the ventral hippocampus produced at the same neonatal age (for review, see Lipska and Weinberger, 2000). In particular, we have observed previously that center distance, a measure thought to represent level of arousal in mice and rats (Paulus et al., 1998; Ralph et al., 2001), was the most consistently altered (increased) behavioral measure in rats with the excitotoxic neonatal lesion. Center distance, reflecting the number of entries to the center of the monitor, which rodents usually avoid, is also the most consistently affected parameter in the TTX rats. The magnitude of TTXinduced behavioral disruptions seems to be smaller, however, compared with those observed after the excitotoxic lesion [e.g., the effect sizes for ibotenic acid lesion-induced spontaneous and amphetamine-induced locomotor activity are 2-3 and 2.5-3, respectively (Cohen's $d$ ) (Lipska et al., 1993; Lipska and Weinberger, 1995), whereas effect sizes of corresponding TTXproduced changes are $0.6-0.8$ and $0.5-0.7]$. Moreover, in contrast to the permanent lesion, TTX infusions did not significantly affect social behaviors, although the trends for reduced social interactions mimicked again a pattern seen after the permanent lesions. A relatively small number of pairs per group in this experiment might have been a reason that we failed to detect a significant difference in this behavior, because the effect size was similar to that seen in animals with the excitotoxic lesion (Cohen's $d=0.8$ and 1.0, respectively). Another possible explanation for the lack of an effect on social behavior is previous exposure to amphetamine, because amphetamines disrupt social patterns in a dose-dependent manner (Miczek and Tidey, 1989). It is possible that previous treatment might have affected social behaviors and blunted the difference between TTX and control rats. The rats in this experiment, however, were exposed to relatively low doses of amphetamine only twice in their lifetime, 1 month apart.

The extent and duration of the functional inactivation induced by the administration of TTX into the immature hippocampus is not known. Previous studies in adult rats using TTX solutions of concentrations similar to those in our experiments showed that the effect of TTX is maximal 30-120 min after the injection (depending on the parameter measured), followed by a slow decline and full recovery after $24-48 \mathrm{hr}$, with the diff usion radius of $1 \mathrm{~mm}$ for a $1 \mu \mathrm{l}$ injection (Zhuravin and Bures, 1991; Ambrogi Lorenzini et al., 1997). It is unclear how such a transient and restricted blockade of ventral hippocampal activity can permanently alter brain function. One possibility is that neonatal blockade affects the development of neurons in the hippocampal formation and interconnected systems that also undergo important maturational changes at this time. Postnatal maturation of the hippocampus of the rat continues into the third week of postnatal life (Schlessinger et al., 1975, 1978; Altman and Bayer, 1990a,b). By that time, there are no longer dramatic increases in neuronal populations and the hippocampus shows adult morphology, although some neurogenesis still occurs in the dentate gyrus during juvenile and adult periods (Bayer et al., 1982). The prefrontal cortex, which receives dense projections from the ventral hippocampus (Jay et al., 1989; Carr and Sesack, 1996), continues to develop well into young adulthood in terms of volumetric changes, growth of dendrites, and formation of synaptic specializations (Uylings et al., 1990). Because the formation of neural networks relies both on molecular signaling (e.g., cell adhesion, chemotropism, repulsion) (Tessier-Lavigne and Goodman, 1996) and electrical (neuronal) activity (Antonini and Stryker, 1993), it is conceivable that transient blockade of electrical activity in one area may alter the structure and function of other interconnected populations of cells. For instance, it was reported recently that blockade of activity by TTX in entorhinohippocampal cocultures during ontogenetic development (slices harvested at P0-P1) disrupts dendritic spine maturation of the target neurons in the dentate gyrus but, interestingly, does not interfere with pathfinding of entorhinal axons (Frotscher et al., 2000). Thus, the maturation of granule cells in the dentate seems to be affected by the electrical activity of afferent fibers. In another study, chronic infusion of TTX into the rat hippocampus (unilaterally into CA3 
area) during postnatal weeks 2 and 3 changed the electrophysiological activity of hippocampal neurons up to $12 \mathrm{~d}$ after completion of TTX infusions and contributed to long-term behavioral changes characteristic of seizures (Galvan et al., 2000). Postnatal weeks 2 and 3 are considered a critical developmental period for the capacity to generate electrographic seizures [the so-called "critical period of CA3 network hyperexcitability" (Swann, 1995)], presumably because of a transient dramatic outgrowth of CA3 axonal arbors that are later pruned. Thus, these data suggest that the blockade of neuronal activity might have halted normal developmental axonal remodeling in the hippocampus (i.e., elimination of exuberant outgrowth of local recurrent excitatory axons).

Another possible explanation for our results is that silencing hippocampal neurons during development may have affected the function of non-neuronal cell populations and thus disrupted normal maturational processes in a widely distributed network. For instance, axonal electrical activity has been implicated in myelination processes. Barres and Raff (1993) have shown that blockade of neuronal activity with TTX injected acutely into the optic nerve of the developing rat dramatically reduced the number of mitotic oligodendrocyte precursor cells (by $>80 \% 2 \mathrm{~d}$ after an injection) and halted axonal myelination. The mechanisms underlying this process are unclear, but it has been proposed that silent axons might fail to signal oligodendrocyte precursor cells to divide by inhibiting stimulation of platelet-derived growth factor and possibly other trophic factors. In the rat fimbria, a major fiber bundle of the hippocampus, myelination occurs largely between P10 and P60. Immunostaining for myelin basic protein is first seen at approximately P7, rapidly increases at P8-P10, and continues to increase until the end of the second month of age (Suzuki and Raisman, 1994). Thus, it is conceivable that an acute TTX infusion at the end of the first week of life, a period of oligodendrocyte proliferation and vigorous myelination processes, might have severely altered the axonal properties of the hippocampal intrinsic and projection neurons during development. However, we have not detected changes in the abundance of myelinated tracts in the young adult hippocampus and surrounding regions (subiculum, entorhinal cortex) of rats that received neonatal TTX infusions. In future studies, we will investigate whether such changes occur early after TTX infusion.

In summary, our data suggest that transient loss of ventral hippocampal function during a critical time in maturation of intracortical connections permanently changes the development of neural circuits mediating certain dopamine- and NMDArelated behaviors. These results represent a potential new model of aspects of schizophrenia without involving a gross anatomic lesion.

\section{REFERENCES}

Al-Amin HA, Weinberger DR, Lipska BK (2000) Exaggerated MK801-induced motor hyperactivity in rats with the neonatal lesion of the ventral hippocampus. Behav Pharmacol 11:269-278.

Al-Amin HA, Weickert CS, Lillrank SM, Weinberger DR, Lipska BK (2001) Delayed onset of enhanced MK-801-induced motor hyperactivity after neonatal lesions of the rat ventral hippocampus. Biol Psychiatry 49:528-539.

Altman J, Bayer SA (1990a) Prolonged sojourn of developing pyramidal cells in the intermediate zone of the hippocampus and their settling in the stratum pyramidale. J Comp Neurol 301:343-364.

Altman J, Bayer SA (1990b) Migration and distribution of two populations of hippocampal granule cell precursors during the perinatal and postnatal periods. J Comp Neurol 301:365-381.

Ambrogi Lorenzini CG, Baldi E, Bucherelli C, Sacchetti B, Tassoni G (1997) Role of ventral hippocampus in acquisition, consolidation and retrieval of rat's passive avoidance response memory trace. Brain Res $768: 242-248$

Antonini A, Stryker MP (1993) Rapid remodeling of axonal arbors in the visual cortex. Science 260:1819-1821.

Barres BA, Raff MC (1993) Proliferation of oligodendrocyte precursor cells depends on electrical activity in axons. Nature 361:258-260.

Bayer SA, Yackel JW, Puri PS (1982) Neurons in the rat dentate gyrus granular layer substantially increase during juvenile and adult life. Science 216:890-892.

Becker A, Grecksch G, Bernstein H-G, Hollt V, Bogerts B (1999) Social behavior in rats lesioned with ibotenic acid in the hippocampus: quantitative and qualitative analysis. Psychopharmacology 144:333-338.

Benes FM (1999) Evidence for altered trisynaptic circuitry in schizophrenic hippocampus. Biol Psychiatry 46:589-599.

Bertolino A, Roffman JL, Lipska BK, Van Gelderen P, Olson A, Weinberger DR (1999) Postpubertal emergence of prefrontal neuronal deficits and altered dopaminergic behaviors in rats with neonatal hippocampal lesions. Soc Neurosci Abstr 25:520.8.

Carr DB, Sesack SR (1996) Hippocampal afferents to the rat prefrontal cortex: synaptic targets and relation to dopaminergic terminals. J Comp Neurol 369:1-15.

Eastwood SL, Harrison PJ (1995) Decreased synaptophysin in the medial temporal lobe in schizophrenia demonstrated using immunoautoradiography. Neuroscience 69:339-343.

Eastwood SL, Harrison PJ (1998) Hippocampal and cortical growthassociated protein-43 messenger RNA in schizophrenia. Neuroscience 86:437-448

Eastwood SL, McDonald B, Burnet PW, Beckwith JP, Kerwin RW, Harrison PJ (1995) Decreased expression of mRNAs encoding nonNMDA glutamate receptors GluR1 and GluR2 in medial temporal lobe neurons in schizophrenia. Brain Res Mol Brain Res 29:211-223.

Eastwood SL, Burnet PW, Harrison PJ (1997) GluR2 glutamate receptor subunit flip and flop isoforms are decreased in the hippocampal formation in schizophrenia: a reverse transcriptase-polymerase chain reaction (RT-PCR) study. Brain Res Mol Brain Res 44:92-98.

Falkai P, Bogerts B (1986) Cell loss in the hippocampus of schizophrenics. Eur Arch Psychiatry Neurol Sci 236:154-161.

Frotscher M, Drakew A, Heimrich B (2000) Role of afferent innervation and neuronal activity in dendritic development and spine maturation of fascia dentata granule cells. Cereb Cortex 10:946-951.

Galvan CD, Hrachovy RA, Smith KL, Swann JW (2000) Blockade of neuronal activity during hippocampal development produces a chronic focal epilepsy in the rat. J Neurosci 20:2904-2916.

Grecksch G, Bernstein HG, Becker A, Hollt V, Bogerts B (1999) Disruption of latent inhibition in rats with postnatal hippocampal lesions. Neuropsychopharmacology 20:525-532.

Harrison PJ (1999) The neuropathology of schizophrenia: a critical review of the data and their interpretation. Brain 122:593-624.

Hori T, Subramaniam S, Carli M, Srivastava LK, Quirion R (1999) Effects of repeated phencyclidine administration on locomotor activity and forced swimming test in rats with neonatal ventral hippocampal lesions. Soc Neurosci Abstr 25:635.8.

Jay TM, Glowinski J, Thierry A-M (1989) Selectivity of the hippocampal projection to the prelimbic area of the prefrontal cortex in the rat. Brain Res 505:337-340.

Lipska BK, Weinberger DR (1993) Delayed effects of neonatal hippocampal damage on haloperidol-induced catalepsy and apomorphineinduced stereotypic behaviors in the rat. Brain Res Dev Brain Res 75:213-222.

Lipska BK, Weinberger DR (1994a) Subchronic treatment with haloperidol or clozapine in rats with neonatal excitotoxic hippocampal damage. Neuropsychopharmacology 10:199-205.

Lipska BK, Weinberger DR (1994b) Gonadectomy does not prevent novelty- or drug-induced hyperresponsiveness in rats with neonatal excitotoxic hippocampal damage. Brain Res Dev Brain Res 78:253-258.

Lipska BK, Weinberger DR (1995) Genetic variation in vulnerability to the behavioral effects of neonatal hippocampal damage in rats. Proc Natl Acad Sci USA 92:8906-8910.

Lipska BK, Weinberger DR (2000) To model a psychiatric disorder in animals: schizophrenia as a reality test. Neuropsychopharmacology 23:223-239.

Lipska BK, Jaskiw GE, Weinberger DR (1993) Postpubertal emergence of hyperresponsiveness to stress and to amphetamine after neonatal hippocampal damage: a potential animal model of schizophrenia. Neuropsychopharmacology 9:67-75.

Lipska BK, Swerdlow NR, Geyer MA, Jaskiw GE, Braff DL, Weinberger DR (1995) Neonatal excitotoxic hippocampal damage in rats causes postpubertal changes in prepulse inhibition of startle and its disruption by apomorphine. Psychopharmacology 122:35-43.

Lipska BK, Al-Amin HA, Weinberger DR (1998) Excitotoxic lesions of the rat medial prefrontal cortex: effects on abnormal behaviors associated with neonatal hippocampal damage. Neuropsychopharmacology 19:451-464.

Miczek KA, Tidey JW (1989) Amphetamines: aggressive and social behavior. NIDA Res Monogr 94:68-100. 
O’Donnell P, Lewis BL, Lerman D, Weinberger DR, Lipska BK (1999) Effects of neonatal hippocampal lesions on prefrontal cortical pyramidal cell responses to VTA stimulation. Soc Neurosci Abstr 25:664.2.

Paulus MP, Geyer MA, Sternberg E (1998) Differential movement patterns but not amount of activity in unconditioned motor behavior of Fischer, Lewis, and Sprague-Dawley rats. Physiol Behav 65:601-606.

Paxinos G, Watson C (1986) The rat brain in stereotaxic coordinates, Ed 2. San Diego: Academic.

Ralph RJ, Paulus MP, Geyer MA (2001) Strain-specific effects of amphetamine on prepulse inhibition and patterns of locomotor behavior in mice. J Pharmacol Exp Ther 298:148-155.

Sams-Dodd F, Lipska BK, Weinberger DR (1997) Neonatal lesions of the rat ventral hippocampus result in hyperlocomotion and deficits in social behaviour in adulthood. Psychopharmacology 132:303-310.

Schlessinger AR, Cowan WM, Gottlieb DI (1975) An autoradiographic study of the time of origin and the pattern of granule cell migration in the dentate gyrus of the rat. J Comp Neurol 159:149-175.

Schlessinger AR, Cowan WM, Swanson LW (1978) The time of origin in Ammon's horn and the associated retrohippocampal fields. Anat Embryol 154:153-173.

Schmued L, Slikker Jr W (1999) Black-Gold: a simple, high-resolution histochemical label for normal and pathological myelin in brain tissue sections. Brain Res 837:289-297.

Stine CD, Lu W, Wolf ME (2001) Expression of AMPA receptor flip and flop mRNAs in the nucleus accumbens and prefrontal cortex after neonatal ventral hippocampal lesions. Neuropsychopharmacology 24:253-266.

Suddath RL, Christisin GW, Torrey EF, Casanova M, Weinberger DR (1990) Anatomical abnormalities in the brains of monozygotic twins discordant for schizophrenia. N Engl J Med 322:789-794.

Suzuki M, Raisman G (1994) Multifocal pattern of postnatal development of the macroglial framework of the rat fimbria. Glia 12:294-308.

Swann JW (1995) Synaptogenesis and epileptogenesis in developing neural networks. In: Brain development and epilepsy (Schwartzkroin PA, Moshe SL, Noebles JL, Swann JW, eds), pp 195-233. New York: Oxford.

Tessier-Lavigne M, Goodman CS (1996) The molecular biology of axon guidance. Science 274:1123-1133.

Uylings HBM, Van Eden CG, Parnavelas JG, Kalsbeek A (1990) The prenatal and postnatal development of rat cerebral cortex. In: The cerebral cortex of the rat. A Bradford book (Kolb B, Tees RC, eds), pp 35-76. Cambridge, MA: MIT.

Weinberger DR (1999) Cell biology of the hippocampal formation in schizophrenia. Biol Psychiatry 45:395-402.

Zhuravin IA, Bures J (1991) Extent of the tetrodotoxin induced blockade examined by pupillary paralysis elicited by intracerebral injection of the drug. Exp Brain Res 83:687-690. 